\title{
A INFÂNCIA NOS CONTOS CHUVAS E TROVOADAS, SOUNDS E MARCEL, DE MARIA LÚCIA MEDEIROS
}

Patricia Cezar da Cruz ${ }^{1}$

\begin{abstract}
RESUMO
A prosa ficcional de Maria Lúcia Medeiros traz 16 contos em que a escritora, nascida no Pará, não se deteve somente na questão regionalista, mas enxergava além do contexto em que vivia. Escreveu contos que trazem contextos e locais de diferentes, uma riqueza de situações e cenários que procuram ser evidenciados pela palavra. Maria Lucia Medeiros trabalha a palavra como um jogo, na poesia que a torna tão significativa. Mas nem sempre essa palavra é dita. Benedito Nunes observa a eficácia estética dos textos da autora, em que a palavra pode adquirir outros sentidos, pode sugerir ou velar a significação literal, de modo que o leitor pode, pelas entrelinhas ou pelo seu horizonte de expectativas, atribuir-lhe novos significados. Este artigo analisa os contos Chuvas e trovoadas, Sounds e Marcel, que trazem um pouco dessa grande habilidade de Maria Lúcia em lidar com a palavra, seus múltiplos significados, a entrelinha e a poesia.
\end{abstract}

Palavras-chave: Literatura juvenil. Poesia. Contos.

\begin{abstract}
The fictional prose of Maria Lúcia Medeiros brings 16 tales in which the writer, born in Pará, didn't work only about the regionalism question but ahead of the context that she lived. She wrote tales about these contexts and different places, a wealth of scenaries and situations evidenced by the word. Maria Lucia Medeiros works the word like a game, in the poetry that makes it significative even if this word is not said. Benedito Nunes shows the stetic efficiency about her texts in which the word can acquire many other meanings, it can suggest or hide the literal signification in a way the reader can read it through their horizon of expectations and give it new significance. This paper provides a reading of the tales Chuvas e trovoadas, Sounds and Marcel which brings a little bit of the great hability of Maria Lúcia in her deal with the word, their multiple meanings and the poetry.
\end{abstract}

Key- words: Juvenil Literature. Poetry. Tales.

\section{A INFÂNCIA NOS CONTOS}

Em Zeus ou a menina e os óculos, obra que reúne 16 contos de Maria Lúcia Medeiros, temos um amplo trabalho com a palavra, que mostra espaços, temáticas, costumes e tempos diferentes, como aqueles que exploram a infância e alguns dos costumes/atitudes que podem ser reconhecidos pelo leitor ou sugeridos aos mesmos como infâncias diferenciadas pela poesia que envolve todo o trabalho da autora.

A infância é relatada nos três contos estudados neste artigo, Zeus ou a menina e os óculos; Sounds e Marcel. No primeiro conto, uma menina míope tem sua visão de mundo alterada quando retira os óculos, deixando a timidez de lado como tantas crianças míopes

\footnotetext{
${ }^{1}$ Doutoranda do Programa de Pós-Graduação em Letras (PPGL) da Universidade Federal do Pará, com área de concentração em Estudos Literários. Mestre em Estudos Literários pela UFPA. Coordenadora do projeto Littera - literaturas germânica e brasileira (CEG-UFPA).E-mail : patricia_cezar@hotmail.com.br
} 
como ela nem sequer pensem em fazer; em Sounds o "menino" cujo nome não é revelado gosta de ouvir sons, os mais diferentes possíveis, passando pelo som da agulha que arranha o disco, o som da torneira, o som do coração. E em "Marcel" temos outro menino francês de origem brasileira, mas que não conhece o idioma português e por isso sente-se à parte da vida de sua família no Brasil. São todos contos envolvidos pelas ficções poéticas.

Benedito Nunes confessa-se enfeitiçado com essas ficções poéticas, gênese de um universo imaginário, onde se ouve sons inaudíveis e se escuta o silêncio, onde se passa dos livros de histórias para a vida ou vice-versa, sendo a melhor ficção a que é capaz de abrir-nos para outras existências, poder da autêntica literatura. Louva a eficácia estética desses textos, a capacidade da narradora para sugerir, para velar a significação literal, para deixar quase sempre o sentido em estado de latência, a significação como que ofuscando o leitor, para além das palavras, onde parte importante do significado está no implícito:

\footnotetext{
Ela consegue pescar com a palavra, como disse a milagrosa pescadora de coisas que foi Clarice Lispector, a entrelinha, o que não é palavra. O embalo rítmico da frase e a sabedoria da elipse sustentam a penetrante poesia de Zeus ou A Menina e os Óculos (NUNES, 1987).
}

O livro Zeus ou a menina e os óculos foi publicado em 1988; esteve presente no currículo escolar das escolas do estado; o título já interage com o leitor ao utilizar a referência mitológica de Zeus, que é uma divindade mitológica grega. É considerado o senhor dos deuses e dos homens que habitavam o monte Olimpo na Grécia antiga; as divindades mitológicas tinham nas mãos o destino dos homens. Regiam o mundo e conduziam o espetáculo da vida. Eram venerados sob a forma terrena, como Zeus, pai dos deuses gregos. Suas histórias atravessaram séculos. Hoje elas são objeto de estudo que buscam explicação humana para fatos e seres sobre-humanos.

Zeus é o mais vingativo dos deuses, é capaz de se metamorfosear, transformando-se em qualquer coisa que quiser, desde animais até seres humanos. É um deus que teve muitos romances e se apaixonou por mortais. Dentre essas uniões estão: Métis, Temis, Dione, Eurinome, Mnemosine, Leto, Hera e Deméter. Seus filhos são Atena, Apolo e Ártemis (Gêmeos), Hermes, Perséfone, Dionísio Perseu, Héracles (Hércules), Helena de Troia, Minos, as Musas, Ares, Hebe e Hefesto, entre outros. Alguns destes oriundos de uniões com mortais. Seus símbolos são o raio, a águia, o touro e o carvalho. É baseado nesse Zeus que Maria Lúcia Medeiros escreveu o conto Zeus ou a menina e os óculos, conto esse que dá nome ao título do livro. 


\subsection{ZEUS OU A MENINA E OS ÓCULOS}

No conto que dá nome ao título, a menina é míope. Quando quer se libertar do cotidiano, ela retira os óculos e viaja sem timidez em um mundo só seu. Assim pode sentir a liberdade de passear sem se preocupar com as pessoas, já que ela não enxerga com nitidez e pode ser ela mesma:

Para o sábado ela se guardava se dava inteira, menina ainda. Ninguém desconfiaria que a menina antes de penetrar no cenário tirava os óculos e, míope, percorria as mesas, vendo as silhuetas dos fregueses, não vendo nariz nem cílios. Ninguém saberia que ela usava óculos de lentes claras e que ela dispensava a nitidez e algumas formas. Que era como se visse tudo pelas suas próprias lentes (ZEUS, p. 29).

Zeus ou a menina e os óculos preza pela questão da liberdade ao retirar os óculos, que provoca mudança, traz segurança porque ela não enxerga e, assim, deixa de ser tímida, como com os óculos.

O sentido da transformação é baseado na capacidade de Zeus de se metamorfosear, por isso mesmo Zeus ou a menina e os óculos. São esses óculos retirados da face que a libertam para ser o que quiser, tal como o deus do Olimpo, como numa transformação.

\subsection{CHUVAS E TROVOADAS}

Neste conto a Literatura provoca o senso comum, que se relaciona com as meninas no sentido de que é comum que elas sejam educadas para serem prendadas, educadas, com "fitas e lacinhos", dentro um padrão educacional da sociedade, como podemos observar nas quatro passagens seguintes;

"Vê-las ali, trabalhos manuais executando, era encher de graça e placidez um mundo de meninas laboriosas, aprendizes, um mundo comportado" (ZEUS, p. 75).

"É claro que, de repente, um pé saía do sapato e escorregava pra baixo da mesa. É claro também que gotas de suor brilhavam naquelas frontes tão claras. Mas entre linhas azuis e verdes, outras matizadas, os ouvidos abriam -se para o ruído das ruas. E passavam vendedores de cascalho. E passavam vendedores de pipoca e havia ainda, quando em vez, bruscas freadas de automóveis. Mas, protegidas do mundo, abrigadas na imensa sala, as meninas costuravam” (ZEUS, p.75). 
"Difícil era fugir à tentação das janelas abertas mas muito altas. Penoso era olhar a um canto o piano sempre fechado, negro, lustroso. Doloroso era ficar tão longe do quintal que se adivinhava lá pro fim do corredor comprido, tábuas corridas enceradas, passadeira colorida, de tão poucos passantes" (ZEUS, p.76)

Há nesses trechos recortados, a presença do comportamento do século XIX, com as meninas que vão bordar; as roupas com bordados, lacinhos nos cabelos, fitas, babados. Educadas, quietas. Teriam "parte com o diabo"? (ZEUS, p.77)

Nessa preparação as meninas seriam "futuras jovens senhoras, mãos de fada, orgulho dos maridos, da família. Proibido falar em mundo perdido" (ZEUS, p.77). O lamento do narrador por não se aproveitar o piano para fazer música; o quintal-surpresa para brincar ou conversar; o silêncio da casa por onde passavam tão poucas pessoas: o ruído que vinha era "triste chegando e enfeitava a tarde calorenta" (ZEUS, p.76) está presente, como numa sugestão de que a vida não são apenas obrigações, mas também aproveitar o que ela oferece, como poder ouvir música, brincar em um quintal ou abrir as janelas para sentir a brisa.

O chamado mundo "luminoso", limpo e confortante, quieto e sem perigos, como mostrado por Hemann Hesse em Demian, é apresentado dentro desta atmosfera de educação e limpeza a qual as meninas estão submetidas. Uma das meninas, porém, fitando o lustre resplandecente, joga a caixinha de costura para o alto e sai na chuva, para perplexidade da professora, e ganha as ruas, onde há chuva: "merda", ela diz, rindo das outras. É essa garota que quebra a expectativa do conto, de modo que este evento inesperado rompe com as perspectivas de que a tarde continuará normalmente, em seu curso cotidiano, porém uma das meninas muda o curso esperado com sua atitude.

Essas "chuvas e trovoadas" que dão nome ao conto indicam não somente um estado da natureza (que pode refletir o "eu" do personagem) mas também a quebra do senso comum, da rotina certinha e monótona a que se pode estar sujeito. Ao sair na chuva, a noção de tomar chuva, de a água molhar as coisas, significaria um renascimento, uma libertação que aparecem nos seguintes elementos:

1. Na antítese quietude $\mathrm{X}$ revolta;

2. No silêncio da sala onde se borda $X$ ruídos das ruas;

3. No lustre resplandecente (da claridade das ideias) $\mathrm{X}$ chuvas e trovoadas (de dentro de si). 
Se descobre neste conto que que, se há imposição de ordem, de organização, controle das coisas, isso é apenas uma utopia. Nem todos nascem para as mesmas coisas e as possibilidades são muitas, inclusive não ser prendada, não casar, não ser exemplo para a família no sentido de ser a "moça perfeita".

A Literatura, através da leitura, liberta de amarras, se quer desbravar novos ares, novos caminhos, novos sentidos para a vida, tal como Robinson Crusoé ser o livro de viagens que a menina que se rebela lê em sua casa.

\subsection{SOUNDS}

Em Sounds lidamos com a expressividade e a estilística. A estilística estuda a expressividade e tem como objeto e a questão do "estilo". Martins (2008) em seus estudos sobre o estilo fala sobre as diversas acepções da palavra enquanto para Buffon o estilo é a própria obra; Estilo é o que há de peculiar e diferencial numa fala (Dámaso Alonso); Estilo é o aspecto do enunciado que resulta de uma escolha dos meios de expressão, determinada pela natureza e pelas intenções do indivíduo que fala ou escreve (Guirand); Estilo é o conjunto objetivo de características formais oferecidas por um texto resultado da adaptação do instrumento linguístico às finalidades do ato específico em que foi produzido (Herculano de Carvalho) (MARTINS, 2008, p. 18-19).

Monteiro (1991, p. 17) acredita que a característica fundamental da expressividade reside na habilidade dos conteúdos de produzir elementos evocatórios ou conotações, por meio de sua força apelativa. Contudo, adverte que a expressividade não está na forma linguística, mas na capacidade evocatória do referente. E exemplifica afirmando que a palavra oceano só é poética por estar associada a uma série de sensações, como imensidão, medo, profundidade etc. Dubois corrobora com essa compreensão afirmando que a capacidade expressiva do material verbal não reside em si mesmo, mas representa a soma das experiências linguísticas do receptor (DUBOIS apud MONTEIRO, 1991, p. 16).

Recortamos dois bons exemplos de expressividade e estilística para melhor compreensão deles aplicados ao texto literário:

"Os ouvidos atentos e ouviam o peito da terra?" ("Não colavam ao chão, os índios, primeiros habitantes primitivos do Brasil, os ouvidos atentos e ouviam o peito da terra?": ZEUS, p.18). Uma alegoria metáfora onde a terra é um corpo vivo, assim como árvore, e devemos escutar o seu coração, as pulsações, a batida, que mais a frente vai ser confirmada com a frase: "E o coração da mãe, do pai, não ouvia?" 
Ouvir a água que corre suave pela torneira: "água escorrendo, a torneira aberta", ou a agulha do toca-discos que corria rápida fazendo um barulhinho estridente: "Mas quando terminava a música e a agulha corria fazendo um barulho que ninguém queria ouvir" (ZEUS, p. 19). Ou o som bonito da flauta ou do piano, que depois de levantada a tampa e tocada a tecla, uma nota sopra, voa do piano, e se expande, ressoando na sala: "uma nota só pra (sopra) vê-la fugir dali, ressoar na sala" provocando uma mistura de sensações sonoras $e$ visuais (as sinestesias).

Efeito de aliteração, a musicalidade das palavras, pode ser observada na passagem: em "som de flauta, assim limpinho, som de tecla de piano, assim sem ser tocado". Outros vocativos também aparecem, chamando pelo "menino", como se também o efeito fosse de aliteração, certa musicalidade ao repetir a palavra " menino":

\section{Desperdiçando água, menino!}

2. Estragando agulha, menino!

3. Olha o piano, menino!

4. Não rasga o livro, menino!

5. Está pensando o quê, menino! Onde se meteu, esse menino! (ZMO, p. 19)

Escutar é a palavra-chave da significação do conto Sounds de Maria Lúcia, escutar o inaudível, o som das palavras, do vento, o som pelo som, e observar a composição rítmica sugerida pelas aliterações, pela mistura das sensações (as sinestesias) e a ampliação do campo semântico pela sonoridade frasal e pelas metáforas. O conto sugere as sensações e o leitor/ ouvinte (seria ouvinte também) abraça a ideia.

\subsection{MARCEL}

$\mathrm{O}$ conto trata de um garoto de origem brasileira, provavelmente nascido e crescido na França (ele só fala em francês) e que estranha o meio em que está (Belém?) e as pessoas que têm reações diferentes das dele como a curiosidade e o típico físico moreno (belenses?), de shorts (porque faz calor). São primos dele, mas ele os estranha; chama pela mãe, mas não ouve resposta (isolamento $\mathrm{X}$ família que ri feliz e come feijoada sem ligar para ele). Possui a barreira da língua, pois não fala em português:

"Parecia coisa do outro mundo. Da grande mala, aberta em cima da cama, pulavam casacões enormes, veludos e lãs, cachecóis. Ao redor dela, de olhos abertíssimos, meninos de 
shorts, rostos suados, morenos corpos se curvavam volteando aquela mala e o dono dela,ali no canto encolhido, as bochechas vermelhas, os braços cruzados, um zíper que fechava o peito, o coração sepultado” ( ZEUS, p. 89).

Com o tempo, Marcel olha para a mala sobre o armário e sente saudade, mas se entretém com os que jogam futebol. Aos 10 anos "eles estavam ali, em cima do bolo de chocolate, em velas que tremulavam e iluminavam um rosto mais feliz, bochechas menos vermelhas. Teve guaraná,sim. E teve fogueira que o avô armou lá no fundo do quintal (.... Dormiu naquele noite entre o estourar de bombas e um cheiro de pólvora queimada, suor, poeira e cinza, canjica nos dentes, um cheiro brasileiro, sim, entre as cobertas. Dormiu tão profundamente que saiu pra escola quase correndo, atrasado para a prova de português" (ZEUS, p.91).

Já adaptado, Marcel estuda a língua portuguesa com mais afinco, de modo que, ultrapassada a barreira linguística, ele pode se identificar com o país e sua língua portuguesa:

"Debruçado à caça de substantivos concretos e abstratos e verbos que se perdiam nas imperfeições dos pretéritos, obrigou-se a ler mais uma vez a Canção do Exílio, dilacerada pela professora. E o que se passou ali, naquele instante, nem sei se vou saber contar (...) Tinha sabiá, avezinha já conhecida do menino. Tinha palmeira (...) tinha gorjeiam e tinha também minha terra". A ideia da identificação do garoto com a terra é reforçada pela ideia de "desarme":

"Desarmou-se. Espingarda (ou lápis?)deixada devagarinho no chão, adentrou estranho reino onde substantivo pode ser adjetivo, plural podia ser singular, e concreto (nem dava para acreditar!)podia ser absolutamente, maravilhosamente, abstrato. O mistério tornara-se doce, o dia mais leve, as questões da prova, uma só questão de provar pra ele mesmo que mundo pode ser grande e pequeno, que o véu pode até cair e virar coisa simples, de repente...(...) Só precisou de dicionário porque precisou saber muito bem sabido, o pressentido. O que exílio quer dizer" (ZEUS, p. 92). Encerra o conto cantando uma canção em português.

Homi Bhabha (2010) propõe que o hibridismo não resolve o embate e o processo de tensão entre duas culturas, não é um novo elemento que surge da junção entre duas matrizes culturais distintas, conforme vemos em Canclini (2011). O hibridismo seria sob esse viés, um processo resultante do choque, do embate, não se trata de um simples processo de adaptação e ressignificação cultural.

Para Stuart Hall (2003) tendo observado em seus estudos a experiência diaspórica vivenciada por Caribenhos rumo à Grã-Bretanha, a hibridização acontece no contexto da 
diáspora e no processo de tradução cultural que os indivíduos vivenciam para se adaptarem às matrizes culturais diferentes da sua de origem. Stuart Hall (2003) propõe que: O hibridismo não se refere a indivíduos híbridos, que podem ser contrastados com os "tradicionais" e "modernos" como sujeitos plenamente formados. Trata-se de um processo de tradução cultural, agonístico uma vez que nunca se completa, mas que permanece em sua indecidibilidade (HALL, 2003, p. 74).

Nesse contexto de análise, o hibridismo não é um processo que traz ao sujeito a sensação de completude ao dialogar com outras culturas, pelo contrário, seria o momento onde o sujeito percebe que sua identidade está sempre sendo reformulada, ressignificada e reconstruída, num jogo constante de assimilação e diferenciação para com o "outro", permanecendo sua indecisão sobre qual matriz cultural o mais representa.

No conto "Marcel", o menino sofre um choque cultural não por motivo de não adaptação ao Brasil ou de rejeitar o país, mas da barreira linguística. Ele só compreende que pertence ao Brasil quando ele consegue sair do exílio em que está a priori por não falar em português. Quando ele consegue compreender a língua, ele se liberta, e sua vida se torna mais tranquila.

Os três contos se conectam pela noção de ruídos: em Chuvas e trovoadas os que vem da rua, como a chuva; em Sounds nome já evidencia os "sons" e em Marcel também pela noção de som da língua que o garoto não compreende. Todos os contos são repletos de cores, sonoridades, sinestesias, e trazem sugestões para o leitor como a de que a Literatura regional deveria estar somente ligada ao que é da Amazônia; se a noção de universalidade, de trocas culturais, é necessária para se compreender que não se pode isolar uma determinada cultura como vemos em Marcel, se em Zeus a pessoa pode se transformar-se ao enxergar por diferentes prismas a vida que se passa.

Como se observa, reiterando o que disse Benedito Nunes, "a melhor ficção é aquela capaz de abrir-nos para outras existências “ (NUNES, 1987, p. XIII) e cada um desses contos sugere, contesta, proporciona novos olhares que podem ser refletidos e contribuir para a noção de ser de cada um.

\section{REFERÊNCIAS}

ACERVO DA GRAPHIA. MARIA LUCIA MEDEIROS. Disponível em: $<$ https://acervodagraphia.wordpress.com/category/maria-lucia-medeiros/ $>$. Acesso em: 03 dez. 2015.

BHABHA, Homi K. O local da cultura. Belo Horizonte: UFMG, 2010. 
HALL, Stuart. A identidade cultural na pós-modernidade. Rio de Janeiro: DP\&A, 2000.

HALL, Stuart. Da diáspora: identidades e mediações culturais. Belo Horizonte: Ed. da UFMG, 2003.

HUTCHEON, Linda. Poética do pós-modernismo. Rio de Janeiro. Imago, 1991. Leitura estilística de Zeus ou a menina e os óculos, de Maria Lúcia Medeiros. Disponível em: $<$ http://cratilo.unipam.edu.br/documents/32405/182548/Leitura++estil\%C3\%ADstica+de+Ze us.pdf >. Acesso em: 03 dez. 2015.

MEDEIROS, Maria Lúcia. Zeus ou a menina e os óculos. São Paulo: Roswitha Kempf Editores, 1988.

TUPIASSÚ, Amarilis (org.). A ficção de Maria Lúcia Medeiros: leituras. Belém: SECULT/IOE, 2002. 